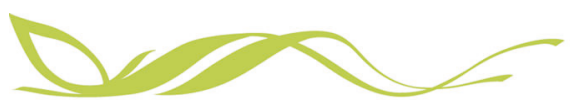

COMMUNICATIONS

EARTH\&ENMRONMENT

ARTICLE

https://doi.org/10.1038/s43247-020-0010-1

OPEN

\title{
Return to rapid ice loss in Greenland and record loss in 2019 detected by the GRACE-FO satellites
}

Ingo Sasgen (10 ${ }^{1 凶}$, Bert Wouters (10) ${ }^{2,3}$, Alex S. Gardner (1) ${ }^{4}$, Michalea D. King (1) ${ }^{5}$, Marco Tedesco ${ }^{6,7}$, Felix W. Landerer (1) ${ }^{4}$, Christoph Dahle (1) ${ }^{8}$, Himanshu Save ${ }^{9} \&$ Xavier Fettweis $^{10}$

Between 2003-2016, the Greenland ice sheet (GrIS) was one of the largest contributors to sea level rise, as it lost about $255 \mathrm{Gt}$ of ice per year. This mass loss slowed in 2017 and 2018 to about $100 \mathrm{Gt} \mathrm{yr}^{-1}$. Here we examine further changes in rate of GrIS mass loss, by analyzing data from the GRACE-FO (Gravity Recovery and Climate Experiment - Follow On) satellite mission, launched in May 2018. Using simulations with regional climate models we show that the mass losses observed in 2017 and 2018 by the GRACE and GRACE-FO missions are lower than in any other two year period between 2003 and 2019, the combined period of the two missions. We find that this reduced ice loss results from two anomalous cold summers in western Greenland, compounded by snow-rich autumn and winter conditions in the east. For 2019, GRACE-FO reveals a return to high melt rates leading to a mass loss of $223 \pm 12 \mathrm{Gt} \mathrm{month}^{-1}$ during the month of July alone, and a record annual mass loss of

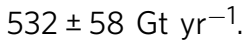

\footnotetext{
${ }^{1}$ Division of Glaciology, Alfred-Wegener-Institut Helmholtz-Zentrum für Polar- und Meeresforschung, Am Handelshafen 12, 27570 Bremerhaven, Germany. ${ }^{2}$ Institute for Marine and Atmospheric research Utrecht, Utrecht University, 3584 CC Utrecht, Netherlands. ${ }^{3}$ Department of Geoscience \& Remote Sensing, Delft University of Technology, 2628 CN Delft, Netherlands. ${ }^{4}$ Jet Propulsion Laboratory, California Institute of Technology, 4800 Oak Grove Drive, Pasadena, CA 91109, USA. ${ }^{5}$ School of Earth Sciences, The Ohio State University, Byrd Polar and Climate Research Center, 123 Scott Hall, Columbus, OH 43210, USA. ${ }^{6}$ Lamont-Doherty Earth Observatory, Columbia University, Palisades, NY 10964, USA. ${ }^{7}$ NASA Goddard Institute for Space Studies, New York, NY 10025 , USA. ${ }^{8}$ Department of Geodesy, GFZ German Research Centre for Geosciences, Telegrafenberg, 14473 Potsdam, Germany. ${ }^{9}$ Center for Space Research at The University of Texas, 3825 Breaker Lane, Suite 200, Austin, TX 78759, USA. ${ }^{10}$ Department of Geography, SPHERES research unit, University of Liège, Liège 4000, Belgium. ${ }^{凶}$ email: ingo.sasgen@awi.de
} 
S tarting in the mid-1990s, the Greenland ice sheet (GrIS) transitioned from a modest contributor to global sealevel, adding $0.21 \pm 0.1 \mathrm{~mm}_{\text {year }}{ }^{-1}$ in the 20th century $(1900-1983)^{1}$ to causing $0.76 \pm 0.1 \mathrm{~mm}$ year $^{-1}$ of the total of $3.5 \pm 0.2 \mathrm{~mm}$ year $^{-1}$ global mean sea-level rise between 2005 and $2017^{2}$, almost equal to the contributions of all glaciers worldwide (2005-2017). One-third of the ice loss is attributed to an $18 \pm 1 \%$ increase of solid ice discharge into the ocean (2010-2018 relative to $1972-2000)^{3}$ and the other two-thirds is attributed to an increase in surface melting that reduced the surface-mass balance (SMB) by $48 \pm 9 \%^{3,4}$. Melt production increases due to a variety of factors, including rising near-surface temperatures ${ }^{5,6}$, reductions in surface albedo 7 , migration of the snow line to higher altitudes $^{8}$, an increase in the total melt area ${ }^{9}$ and cloud-radiative effects $^{10}$. Global climate models project Arctic annual temperatures to rise about two and a half times faster compared to the tropics, with a factor of one and a half estimated for the summer months only ${ }^{11}$. GRACE and GRACE Follow-On (GRACE-FO) enable us to quantify the ice sheet response to meteorological forcing on sub-annual time scales, helping to improve our understanding of feedbacks between surface processes and ice dynamics that are highly relevant for projecting mass changes of the GrIS.

Numerous studies have quantified the contemporary mass loss of the GrIS using different satellite-based Earth observations ${ }^{3,12-14}$. The consensus of these studies is that the GrIS has lost an average of $-148 \pm 13 \mathrm{Gt}$ year $^{-1}$ of ice from 1992 to 2018 , with total losses (meltwater runoff and ice discharge) recently (2003-2016) exceeding total gains (snowfall) by more than one third ${ }^{13}$. The GRACE/ GRACE-FO time series provides evidence for an acceleration of mass loss from 2003 until 2012, caused by an increase in both the flowspeed of glaciers draining the ice sheet and melting at their surface ${ }^{15}$. Enhanced melt production correlates with more frequent anticyclonic circulation anomalies in mid-troposphere that are in-turn related to the presence of stable high-pressure systems over Greenland ('Greenland blocking') ${ }^{16}$. Although such changes are not projected by global models, anticyclonic conditions prevailed in about half of all summers since the end of the $1990 \mathrm{~s}^{17}$. For example, the sizeable mass losses in 2010 and 2012, $-462 \pm 60 \mathrm{Gt}$ year $^{-1}$ and $-464 \pm 62 \mathrm{Gt}$ year $^{-1}$ respectively as measured by GRACE, were conditioned by an exceptional persistent high-pressure system over Greenland, forcing warm air from mid-latitudes along the west coast of the ice sheet ${ }^{18}$, along with cloud radiative effects ${ }^{19,20}$. Strong melt-albedo feedbacks amplified the response of the surface-mass balance to the atmospheric drivers, favouring anomalously dry and sunny summers over the ice sheet ${ }^{21,22}$.

In situ and remote sensing observations have previously documented the anomalous GrIS surface conditions in 2017 and $2018^{13}$. However, with end of science operations of the GRACE mission in June 2017, mass balance estimates from observations remained highly uncertain for that period. The GRACE-FO mission was launched on May 22, 2018. GRACE-FO mirrors the GRACE mission concept of two satellites measuring the variations in their along-track distance caused by differences in Earth's gravitational attraction using a microwave ranging system, recording redistributions of water and ice on the Earth surface $^{23,24}$. As a technical demonstration, GRACE-FO is additionally equipped with a laser interferomer ranging system, currently being tested to facilitate more accurate tracking of the inter-satellite distance and, potentially, enable better-resolved gravity fields ${ }^{25}$. Both missions record nearly independent mass changes for distances greater than $\sim 300 \mathrm{~km}$. For the $\mathrm{GrIS}^{26}$, GRACE/GRACE-FO mass changes are typically separated into six to eight drainage basins ${ }^{13,27,28}$. Because the GRACE-FO mission is able to track changes in gravity since the end of the GRACE mission, the most recent GRACE-FO measurements represent the cumulative mass change occurring between the last GRACE and first GRACE-FO observation. This allows quantification of the combined mass balance for 2017 and 2018.

Here, we show that early data from GRACE-FO compared to GRACE reveal a 58\% slowdown in GrIS mass loss in 2017-2018 $\left(-98 \pm 29 \mathrm{Gt}\right.$ year $\left.^{-1} ; \pm 2 \sigma\right)$, similarly indicated by satellite altimetry records ${ }^{5}$. Using regional climate modelling output ${ }^{6}$, we show that reduced losses in 2017 and 2018 result from two anomalous cold summers in western Greenland compounded by snow-rich autumn and winter conditions in the east. For 2019, GRACE-FO reveals a return to high rates of loss with a mass change of $-223 \pm 12 \mathrm{Gt}^{\text {month }}{ }^{-1}$ during the month of July alone. We further explain how changes in synoptic conditions influence rates of loss; intensified summer cyclonic circulation over Greenland in 2017 and 2018 favoured southward movement of colder air masses along the melt-sensitive western flank of the GrIS. In summer 2019, conditions were largely reversed with a dominance of anti-cyclonic conditions over the ice sheet, similar to 2012, advecting warm mid-latitude air masses to northwestern Greenland. Combined with low snowfall, 2019 sets a new record GrIS annual mass balance of $-532 \pm 58 \mathrm{Gt}$ year $^{-1}(-464 \pm 62 \mathrm{Gt}$ year $^{-1}$ in 2012), unprecedented in 1948-2019 and probably within the 20th century ${ }^{7}$. Despite the slowdown recorded in 2017 and 2018 and large year-to-year variability, the rapid mass loss in 2019 recorded by GRACE-FO indicates the GrIS has remained on a trajectory of increasing mass loss since the late 1990s in response to Arctic warming.

\section{Results}

Satellite gravimetry and regional climate models. Figure 1 presents the time series of mass change of the GrIS derived from 180 monthly GRACE and GRACE-FO gravity solutions (2002-2019) ("Methods" section). Using a piecewise linear model, we estimate biennial mass balances starting in January 1st of each year, centred on the strongest cumulative loss in July ("Methods" section). The estimate for 2017-2018 contains the five last months of GRACE data and the first five from GRACE-FO in 2018, even though gravity fields at the end of 2017 have higher uncertainties due to partial instrument failure (loss of accelerometer on GRACE-B satellite). The biennial mass balance averaged for the entire observation period is $-235 \pm 29 \mathrm{Gt}_{\text {year }}{ }^{-1}$. The year 2012 marks a pronounced mass balance anomaly; mass loss increases to a peak biennial rate of $-437 \pm 26 \mathrm{Gt}$ year $^{-1}$ in 2011 and 2012 and slow to an average rate of $-143 \pm 17 \mathrm{Gt}^{-1}$ year $^{-1}$ during the following 6 years (2013-2018). Rates of loss were especially low during the 2017-2018 period when GRACE and GRACE-FO detect an average rate of change more than four times less negative $\left(-98 \pm 26 \mathrm{Gt}_{\mathrm{Hear}}{ }^{-1}\right)$ than the peak rates observed in 2011-2012. Nevertheless, all 2003-2018 biennial mass balances showed a statistically significant mass loss at the $5 \%$ confidence level.

To determine the cause of the 2017-2018 slowdown in rates of loss, we compare the GRACE/GRACE-FO time series with monthly mass budgets of the ice sheet. The SMB from the regional climate models MARv3.10 $0^{29,32}(20 \mathrm{~km}$ resolution; forced by NCEP-NCARv1 reanalysis ${ }^{33}$ ) and RACMO2.3p2 ${ }^{30}$ (statistically downscaled from $5.5 \mathrm{~km}$ to $1 \mathrm{~km}$; forced by ECWMF reanalysis ${ }^{34}$ ) ("Methods" section), is contrasted against solid ice discharge (D) into the ocean, as estimated at sub-annual temporal resolution from feature tracking of optical and radar imagery ${ }^{31}$. The combination of SMB-D equals the net mass balance as observed by GRACE/GRACE-FO ${ }^{4}$. To account for possible biases in SMB and $D^{35,36}$ or the glacial-isostatic adjustment correction of the gravity fields ("Methods"), we apply a linear trend correction to the SMB-D data to reconcile with the 


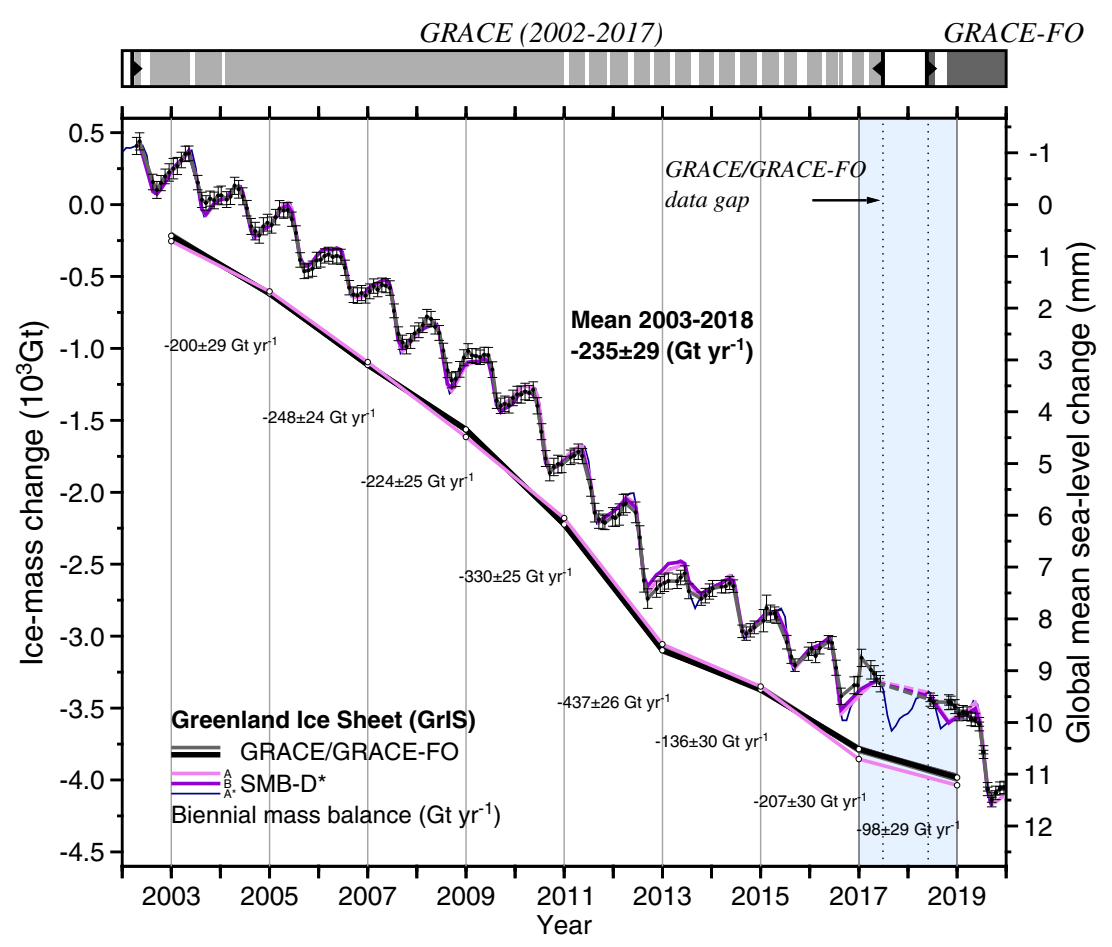

Fig. 1 Mass changes of the Greenland Ice Sheet between 2002 and 2019. Time series of mass change from the GRACE and GRACE-FO missions (black, with $2-\sigma$ error bars) and simulations using the regional climate models MARv3.10 30 ( $\mathrm{A}$; light violet) and RACMO2.3p2 ${ }^{31}$ ( $\mathrm{B}$; dark violet) and calibrated outflow measurements from feature tracking of optical and radar imagery (SMB-D*), updated from 32 ("Methods" section). The top bar indicates the availability of GRACE and GRACE-FO measurements, the vertical dashed lines frame the data gap between both missions. The blue shading covers the biennial period 2017-2018, which contains the GRACE/GRACE-FO data gap (dotted line). The monthly SMB-D* data shown for MARv3.10 (A*; dark blue) are linearly interpolated to match the GRACE/GRACE-FO measurement timeframes. Both datasets are fitted with a biennial piecewise linear trend (breakpoints on January 1st of each year), revealing accelerated mass losses until 2012, followed by a slowdown and particularly small loss during the years 2017 and 2018. Values denote biennial mass balances in $\mathrm{Gt}_{\text {year }}{ }^{-1}$.

GRACE/GRACE-FO trends between 2003 and 2019, now denoted as SMB-D*. The amounts to -7 Gt year ${ }^{-1}$ for RACMO2.3p2 and $52 \mathrm{Gt}_{\text {year }}{ }^{-1}$ for MARv3.10, but generally is dependent on model type, model version, and model forcing (Methods). In addition, SMB-D* values are linearly interpolated to the GRACE/GRACE-FO measurement epochs. The biennial mass balances from SMB-D* data confirm the relative slowdown of loss in the period 2017-2018 observed by GRACE/GRACE-FO (Fig. 1). In contrast to Velicogna et al. ${ }^{14}$ we find that the deviations between GRACE/GRACE-FO and SMB-D* biennial mass balances of 2017-2018 (-12 Gt year ${ }^{-1}$ for RACMO2.3p2; +7 Gt year ${ }^{-1}$ for MAR3.10) lie within the error bars of the GRACE/GRACE-FO observations, in support of an unbiased continuation of the time series from GRACE to GRACE-FO.

Biennial mass balance anomalies. We now focus on the anomalies of the biennial mass anomalies and their components with respect to their corresponding 2003-2018 mean values (Fig. 2). For GRACE/GRACE-FO the 2003-2018 mean is $-235 \pm$ $29 \mathrm{Gt}$ year $^{-1}$, as indicated in Fig. 1. In the GRACE/GRACE-FO record, the mass balance period 2017-2018 stands out with a positive anomaly (reduced mass loss) of $+137 \pm 25 \mathrm{Gt}_{\text {year }}{ }^{-1}$, followed by the years $2013-2014\left(+99 \pm 25 \mathrm{Gt}\right.$ year $\left.^{-1}\right)$. For 2018 alone, annual rates from SMB-D* indicate near-balance of -19 Gt year $^{-1}$ (MARv3.10). GRACE/GRACE-FO shows the most negative biennial anomaly of $-202 \pm 24 \mathrm{Gt} \mathrm{year}^{-1}$ for 2011-2012, double the average rate of mass loss.

To identify the processes underlying these anomalies, we separate the SMB-D* into its components of net accumulation (snowfall minus evaporation and sublimation), meltwater runoff (surface melt minus refreezing and retention), and solid ice discharge $\left(D^{*}\right)$.

Figure 2 shows that the reduced mass loss in 2017-2018 is caused by both enhanced accumulation between 56 and $88 \mathrm{Gt}$ year $^{-1}$ (red bars in Fig. 2) and reduced meltwater runoff between +65 and 78 Gt year ${ }^{-1}$ (green bars in Fig. 2). The magnitudes of these anomalies are not exceptional over the study period-a comparable anomaly in snowfall and meltwater runoff occurred in 2003-2004 and 2013-2014 respectively. What is exceptional over the period of study is the occurrence of strongly positive snowfall and meltwater runoff anomalies in the same years. From 2003 to 2018 , net runoff controls the largest variability in rates of biennial mass change ( \pm 61 to $69 \mathrm{Gt}$ year $^{-1}$ of \pm 83 to $98 \mathrm{Gt}$ for SMB-D*), indicating a high sensitivity of the ice sheet to summer atmospheric forcing and changes in the surface radiation budget. The variability of biennial snowfall is only slightly lower at \pm 39 to $52 \mathrm{Gt}$ year $^{-1}$.

The GRACE/GRACE-FO and SMB-D* mass anomalies in Fig. 2 show a striking regional difference in changes that are driven by snowfall in the east and melt in the west of Greenland. In fact, nearly all (72-88\%) of the snowfall anomaly (+65 and 78 Gt year $^{-1}$ ) in 2017-2018 occurred on the east and southeast sectors of the ice sheet, whereas $71-77 \%$ of the runoff anomaly occurred in the west and southwest $\left(+50-55\right.$ Gt year $\left.{ }^{-1}\right)$. This spatial pattern of snow and melt anomalies are congruent with the climatic divide of the GrIS, with SMB variability dominated by snowfall in the east and melt in the west ${ }^{29,37}$. Ice discharge shows a slowdown of $7 \mathrm{Gt}$ year $^{-1}$ within the biennial period 2017-2018, largely due to the slowdown of Greenland's largest glacier $^{38}$, but remains close to the 2003-2018 average. 


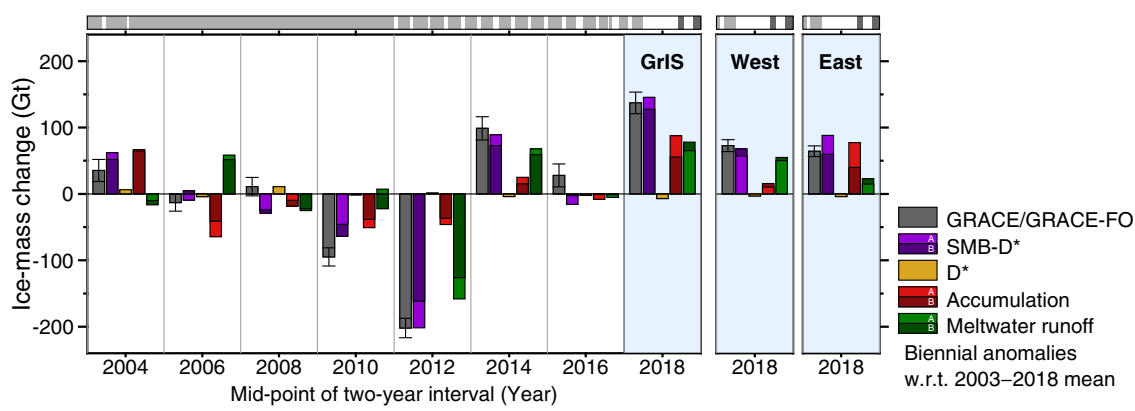

Fig. 2 Biennial mass balance anomalies and individual components for the Greenland Ice Sheet between 2003 and 2019. Shown are anomalies of the biennial mass balance from GRACE/GRACE-FO, with 2- $\sigma$ error bars, and SMB-D* along with the components of accumulation, meltwater runoff and solid ice discharge $\left(D^{\star}\right)$, with respect to their corresponding 2003-2018 mean values. For GRACE/GRACE-FO the $2003-2018$ mean is $-235 \pm 29$ Gt year -1 . Shown are results for MARv3.10 (A) and RACMO2.3p2 (B). The period 2017-2018 stands out with the most positive mass loss anomaly of $+137 \pm 25$ Gt year $^{-1}$, caused in equal parts by enhanced snowfall and reduced meltwater runoff in the eastern and western drainage basins, respectively ${ }^{37}$. The top bar indicates the availability of GRACE and GRACE-FO measurements.

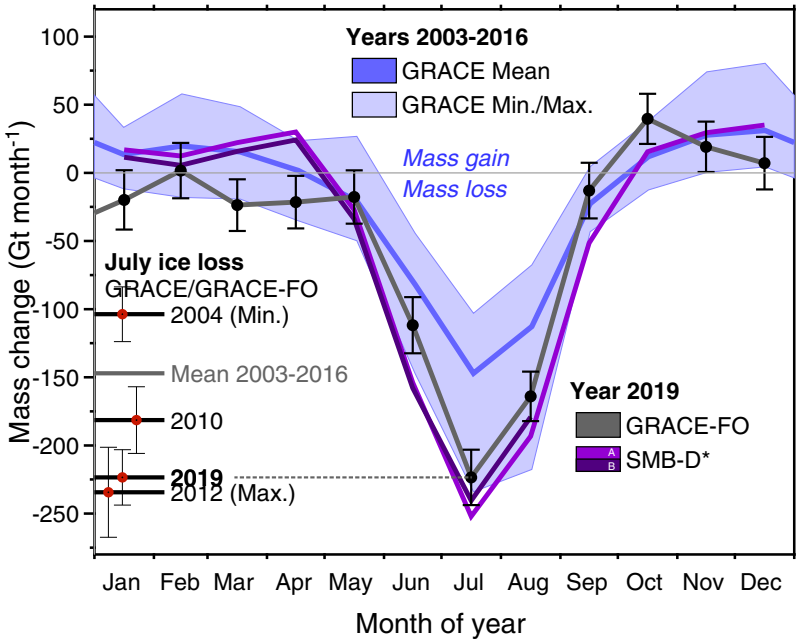

Fig. 3 Monthly mass change of the Greenland Ice Sheet for the year 2019 and average rates for the years 2003 to 2016. Shown are monthly mass changes for GRACE-FO (black, with 2- $\sigma$ error bars) and SMB-D* (light violet: MARv3.10; dark violet RACMO2.3p2) from January to September 2019, along with the seasonal climatology from GRACE for 2003-2016. A positive mass change represents accumulation; a negative mass change indicates ablation. July 2019 ranks as the summer month with the second largest mass loss recorded by GRACE/GRACE-FO (red dots), exceeded only by 2012, and followed by 2010. Because of gaps in the GRACE/ GRACE-FO record of mass change, July mass changes are known for 2004 through 2010, 2012, 2016, and 2019 (13 years in total).

A return to rapid losses in 2019. Conditions abruptly changed in 2019, from cold and snow rich in the 2017-2018 period, approaching a record rate of summer mass loss (Fig. 1). After the science data collection was interrupted for about three months in the early mission phase, GRACE-FO picked up continuous highquality measurements in October 2018, allowing the estimation of monthly resolved rates of mass change. Figure 3 shows monthly mass anomalies in 2019, estimated as temporal derivative of the GRACE-FO and SMB-D* mass time series using a central difference scheme ("Methods" section). For comparison, we show the climatological mean of the seasonal variation recorded with GRACE between 2003 and 2016. From January to May 2019, GRACE-FO observed a slight mass loss, nearly constant and below the average 2003-2016 values, pointing towards reduced accumulation or an early onset of melt, however, not supported by the SMB-D* estimates. In June and July 2019, the ice sheet experienced anomalously high rates of meltwater runoff close to the maximum rates observed over the full 2003-2018 period. GRACE-FO measurements reveal a peak mass change in July 2019 of $-223 \pm 23 \mathrm{Gt}$ month $^{-1}$ (51 \% more negative than the climatological average 2003-2016), ranking second only behind the record melt year $2012\left(-234 \pm 35 \mathrm{Gt}^{\text {month }}{ }^{-1}\right)$ and followed by $-181 \pm 27 \mathrm{Gt} \mathrm{month}^{-1}$ in 2010 . For comparison, in the years with sufficient monthly coverage, GRACE observed minimum

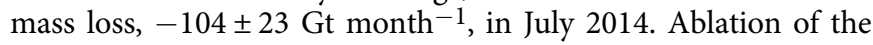
GrIS continued through August and September 2019, entering accumulation conditions in early October, similar to the GRACE climatology (2003-2016).

With completion of 2019, GRACE-FO measures a new record January to December 2019 GrIS mass loss, $-532 \pm 58 \mathrm{Gt}_{\text {year }}{ }^{-1}$, $15 \%$ more negative than the previous record year of 2012, supported by SMB-D* values of $-542 \mathrm{Gt}$ year $^{-1}$ (MARv3.10).

\section{Discussion}

Warming of the Arctic over the past few decades has exceeded global average rates of warming, decreasing the near-surface air temperature gradient to the mid-latitudes by about $2{ }^{\circ} \mathrm{C}^{39,40}$. Similar amplification, with factors ranging from one and a half in summer to three and a half in winter, is projected for the end of the century with contributions from various processes ${ }^{11,41}$. Today, circulation in the Arctic exhibits more stable highpressure systems and associated atmospheric blocking over Greenland in summer, as reflected by the Greenland Blocking Index ${ }^{16}$, enhancing anticyclonic circulation and advection of warm, continental mid-latitude air masses along the west coast of Greenland $^{42}$. Figure 4 shows such a circulation anomaly for the summer months (JJA) of 2019, substantially affecting the mass balance of the ice sheet as recorded by GRACE-FO. Similar atmospheric conditions prevailed in $2012^{43}$, with the impact shown in Figs. 1 and 2. In 2017 and 2018 (Supplementary Fig. 1), circulation anomalies showed largely reverse conditions compared to 2012 and 2019; the summer months exhibited a strong low-pressure anomaly over Greenland, forcing cold Arctic air more southward along its west coast (Fig. 4). Consequently, temperatures were anomalously low in the summer months of 2017 and 2018, relative to 2002-2016, reducing melt production and the related mass loss. Similar synoptic patterns can also explain the pause of the GrIS mass loss in $2013^{43}$, after the peak melt in the summer of $2012^{44}$.

The time series of GRACE/GRACE-FO GrIS mass anomalies documents an abrupt transition from a reduced rate of mass loss in 2017-2018 (58\% lower than 2003-2018 average) to a strongly enhanced rate of mass loss in 2019 (July mass loss rate $51 \%$ above 2003-2016 average). A similar but inverse transition occurred 

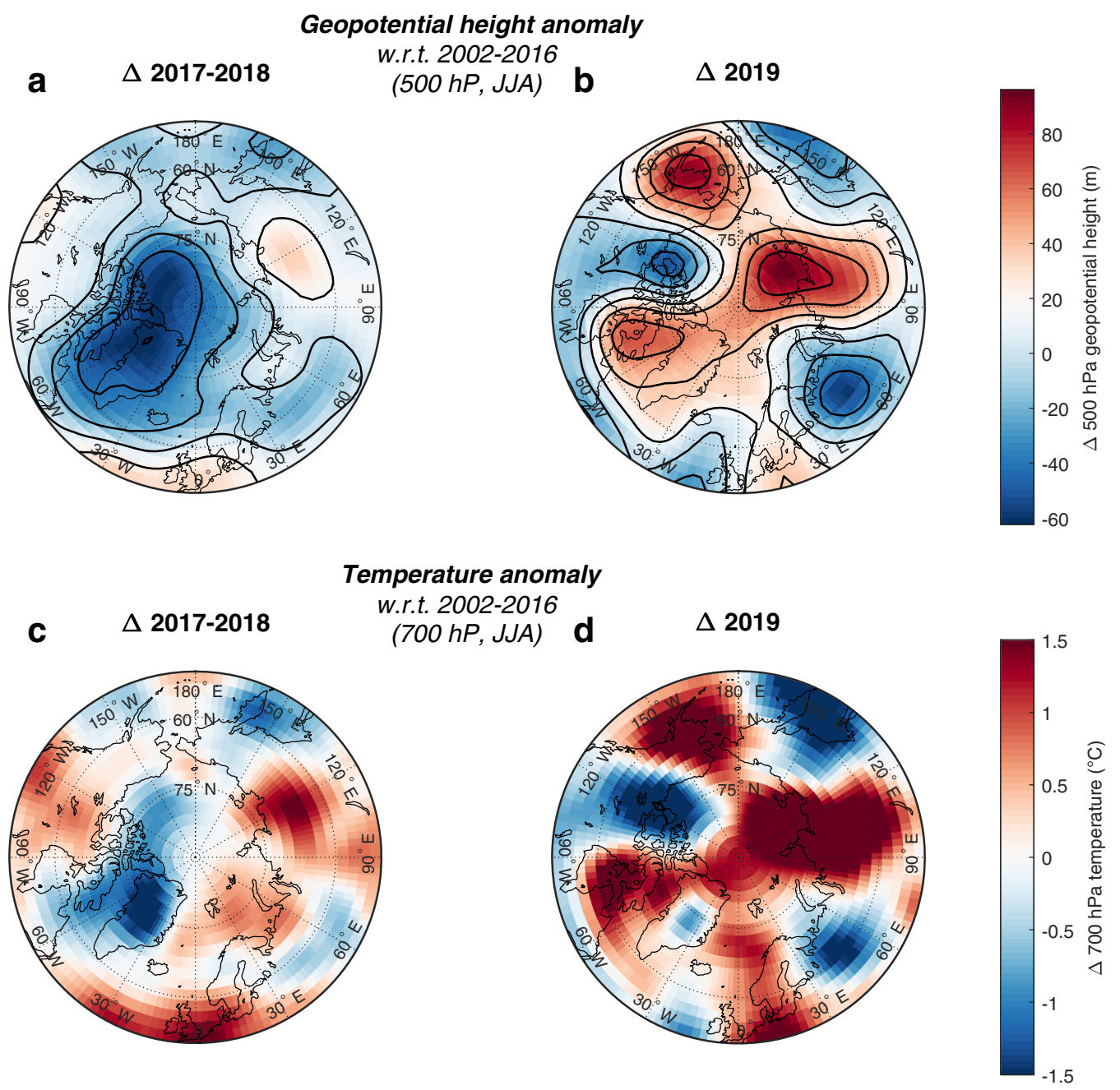

Fig. 4 Atmospheric conditions over the Arctic in summer for the low melt years of $\mathbf{2 0 1 7}$ and $\mathbf{2 0 1 8}$ and the strong melt year of 2019. Shown are summer mean (JJA) anomalies relative to 2002-2016. In 2017 and 2018, a $500 \mathrm{hPa}$ geopotential height shows a pronounced low over Greenland, promoting below average (2002-2016), c temperatures at $700 \mathrm{hPa}$. In 2019, the pattern reversed with a higher, b $500 \mathrm{hPa}$ geopotential height, accompanied by significantly warmer, $\mathbf{d}$ temperatures at $700 \mathrm{hPa}$ in western Greenland. Thick black lines in $\mathbf{a}$ and $\mathbf{b}$ are contours of the anomaly of the $500 \mathrm{hPa} g e o p o t e n t i a l$ height spaced at intervals of $20 \mathrm{~m}$.

between the record melt year of 2012 and the near-balance year of $2013^{44}$. Figure 5 shows that the GRACE-FO annual balance of 2019 (Jan 1st to Jan 1st) amounted to $-532 \pm 58 \mathrm{Gt}^{-1}$ year $^{-1}$, exceeding the previous record loss of $-464 \pm 62 \mathrm{Gt}^{\text {year }}{ }^{-1}$ measured by GRACE in 2012. SMB-D* indicates that meltwater runoff and discharge were similar in 2012 and 2019 (-707 Gt year $^{-1}$ and $-693 \mathrm{Gt}^{\text {year }}{ }^{-1}$ ), confirming previous analysis covering the melt season until September 201914. However, 2019 showed $107 \mathrm{Gt}$ year $^{-1}$ less snow accumulation than 2012, with accumulation rates in September and October 2019 below the 2002-2016 average. Figure 5 shows that 2019 exhibited the largest mass loss on record, following a the trajectory of increasing ice loss since late 1990s. Within 1948-2019, the top five loss years of the GrIS occurred in the past ten years $(2019,2012$, 2010, 2011 and 2016). In this context, 2017 and 2018 mass balances have to be considered rare excursions to near balance conditions that have occurred often before the late 1990s.

The modulation of the mass balance of the GrIS is a substantial response of accumulation and melt processes to changes in atmospheric forcing and a strong Arctic warming trend, further accentuated by feedbacks within the ice sheet/climate system, such as the ice-albedo and, on longer time scales, the ice-elevation feedback ${ }^{45}$. These changes are superimposed on substantial trends in solid ice discharge driven by climate-related (ocean and atmosphere) changes in frontal melting and terminus retreat ${ }^{31,46,47}$. Our study highlights that prolonged observations from GRACE/GRACE-FO and other satellite missions, together with modelled SMB are crucial to understand and quantify the processes controlling the ice sheet's response to changing meteorological conditions in the Arctic. Such insights will ultimately lead to improved model representation of the Arctic climate system in global projections of sea-level change.

\section{Methods}

GRACE/GRACE-FO data. Mass variations of the GrIS from 2002 to 2019 are estimated using data from the GRACE (2002-2017) and the GRACE-FO (launched 2018 , operational) missions that provide nearly continuous measurements of the Earth's gravity field at monthly time intervals. These measurements, facilitated as Level-2 data by the missions' Science Data System (SDS) teams in the form of Stokes potential coefficients, can be directly related to mass redistribution on the Earth's surface ${ }^{23,24}$. We use Release 06 (RL06) Level-2 data from the three GRACE/ GRACE-FO SDS teams; German Research Centre for Geosciences (GFZ) ${ }^{48}$, Centre for Space Research University of Texas, Austin, USA (CSR) ${ }^{49,50}$ and Jet Propulsion Laboratory, California Institute of Technology (JPL) ${ }^{51}$. The data cover 180 months out of 207 possible months during mission operation, 163 solutions from GRACE covering April 2002 to June 2017 and 17 solutions from GRACE-FO covering June 2018 to December 2019 (Data availability). This study does not find a bias or offset between the results of both missions (Supplementary Fig. 2). 


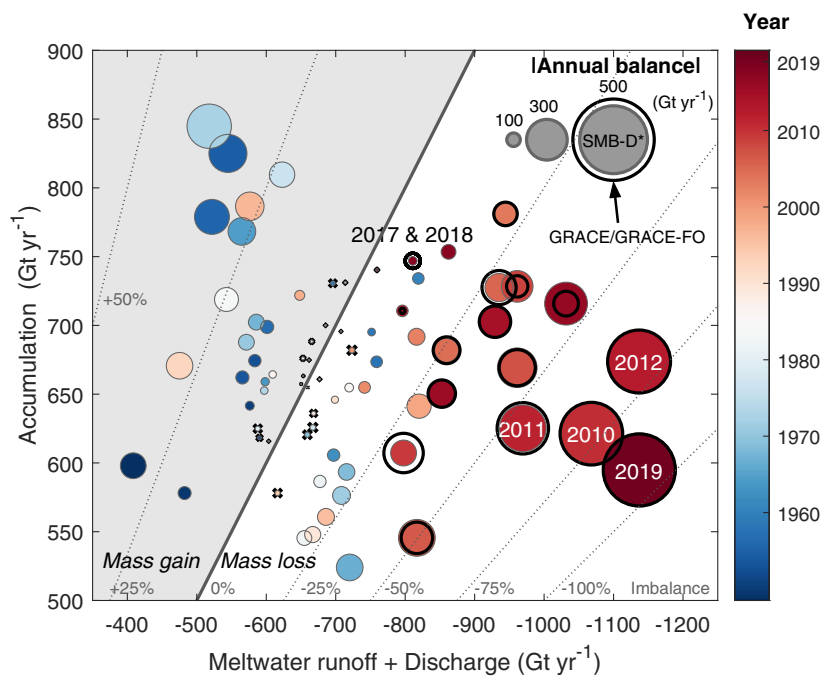

Fig. 5 Annual mass balances and driving components of the GrIS. Shown are annual mass balances from SMB-D* (1948-2019; 2017 \& 2018 mean also indicated; MARv3.10) and GRACE/GRACE-FO (2003-2019, only mean for 2017 \& 2018 indicated), along with the primary components of inflow (accumulation) and outflow (meltwater runoff + discharge). The size of the filled circles, colour-coded by year, indicates SMB- $D^{\star}$, and the marginal ring estimates from GRACE/GRACE-FO. The diagonal line indicates balance conditions for the GrIS, years with mass gain fall into the grey shaded area. Dashed grey lines indicate the imbalance state of the GrIS, represented as the ratio of the mass balance versus annual inflow through accumulation (\%). Near balance years $\left(< \pm 50 \mathrm{Gt}_{\text {year }}{ }^{-1}\right)$ are indicated by crosses.

GRACE/GRACE-FO corrections. We use Stokes potential coefficients $C_{j m}$ up to degree, $j$, and order, $m, 60$ and apply the following common corrections to the Level-2 data: (1) Insertion of degree-1 $(j=1)$ coefficients-which are not recovered by GRACE/GRACE-FO-provided by the SDS based on Sun et al. ${ }^{52}$, an improvement to the estimation method originally proposed by Swenson et al. ${ }^{53}$. These data are available as GRACE Technical Note 13 from https://podaac-tools.jpl. nasa.gov/drive/files/GeodeticsGravity/gracefo/docs/ for each SDS data set. (2) Replacement of highly uncertain $\mathrm{C}_{20}$ coefficients from GRACE/GRACE-FO by more accurate estimates from Satellite Laser Ranging (SLR) ${ }^{54}$, accessible as GRACE Technical Note 14 from https://podaac-tools.jpl.nasa.gov/drive/files/ GeodeticsGravity/gracefo/docs/TN-14_C30_C20_GSFC_SLR.txt.

Note that although the replacement of $\mathrm{C}_{30}$ coefficients is recommended by the GRACE/GRACE-FO SDS centers for solutions starting August 2016, this issue is still under discussion from the user point of view since it introduces a discontinuity in the time series between months with nominal and anomalous GRACE/GRACEFO accelerometer performance ${ }^{55,56}$. In this study, we do not adopt this procedure, as it moderately increases the difference with the modelled mass balance for the year 2019, while slightly decreasing the difference for 2016. For completeness, we state that replacing the GRACE/GRACE-FO $\mathrm{C}_{30}$ coefficients with the SLR estimates provided in GRACE Technical Note 14 changes the temporal linear trend from $-225 \mathrm{Gt}_{\text {year }}{ }^{-1}$ to $-213 \mathrm{Gt}_{\text {year }}{ }^{-1}$ for the time period August 2016 to December 2019. The linear trend for April 2002 to December 2019 changes by less than $1 \mathrm{Gt}_{\text {year }}-1$.

The GRACE/GRACE-FO gravity fields are corrected for long-term mass trends caused by the Earth's viscoelastic relaxation to past changes in ice loading, the glacial-isostatic adjustment (GIA), using the GGG1.D model ${ }^{57}$. GGG1.D is tuned to fit measured GIA-induced uplift rates and represents a rate of gravity field change equivalent to $+16 \mathrm{Gt}_{\text {year }}^{-1}$ of ice mass change over Greenland (Supplementary Fig. 3). The spread of ten GIA corrections presented in ${ }^{13}$ ranges from -28 to $+27 \mathrm{Gt}_{\text {year }}{ }^{-1}$ with a mean of $-5 \mathrm{Gt}_{\text {year }}{ }^{-1}$. As conservative uncertainty estimate, the standard deviation of $\pm 17 \mathrm{Gt}_{\text {year }}^{-1}$ is included in the presented GRACE/GRACE-FO annual and long-term trends.

GRACE/GRACE-FO solution combination. To reduce the noise level of the solutions and mitigate the impact of possible outliers ${ }^{58}$, we estimate 180 combined GRACE/GRACE-FO monthly solutions (AV RL06). This combination is achieved by coefficient-wise weighting of the Stokes potential coefficients $C_{j m}$ from SDS centers $\left(N_{s o l}=3\right)$ for each time $t$, according to $C_{j m}^{A V, t}=\sum_{n=1}^{N_{s o l}}\left(w_{j m}^{n, t} C_{j m}^{n, t}\right) / \sum_{n=1}^{N_{s o l}} w_{j m}^{n, t}$, where $w_{j m}^{n, t}$ represent weights corresponding to the inverse of the squared variance of the calibrated uncertainty of each coefficient, $\hat{\sigma}_{j m}^{n, t^{-2}}$. Formal uncertainties provided with the GRACE/GRACE-FO coefficients result from different estimation procedures that prevent their direct use as quantitative weights. Therefore, we calibrate the uncertainties based on the noise level of each solution as follows; we estimate the temporal residual, .. after subtracting bias, trend, annual, semiannual and temporal variations longer than four months (using a moving average filter) from the GRACE/GRACE-FO coefficients' time series. We then determine the degree power in the noise-dominated spectral range $\left(j_{\min }=40\right.$ to $\left.j_{\max }=60\right)$ acccording to $\sum_{j=j \min }^{j \max } \sum_{m=-j}^{j}\left(C_{j m}^{\text {Res. }}\right)^{2}$, which is representative of the noise level in each solution. The formal uncertainties provided with the SDS centers are then calibrated by a single scaling factor to match the degree power of the residual estimated for GRACE/GRACE-FO coefficients, yielding $\hat{\sigma}_{i m}^{n}$. This approach adopts the error structure from the formal uncertainties with the error magnitude estimated from the residual.

We carry out the combination on detrended data, as the differences in the trends appear to be systematic and arising from different processing choices of the SDS centers (Supplementary Fig. 4). Therefore, the monthly weights derived from coefficients beyond degree and order 40 are not representative for the relative uncertainty of the trends. Applying these weights to the different temporal linear signals would introduce artificial monthly temporal variability of about $2 \mathrm{Gt}$. Therefore, we remove the trends before combination and restore them, assuming equal weights for each SDS center, in the combined solution, $C_{j m}^{A V}$.

The GrIS mass change time series for the SDS solutions GFZ RL06, CSR RL06 and JPL RL06, as well as their combination AV RL06 are shown in Supplementary Fig. 4.

Gravimetric inversion. To retrieve the mass anomalies at a regional scale from the GRACE/GRACE-FO coefficients, we apply an inversion scheme based on forward modelling, using low-frequency damping and a non-uniform a priori mass distribution of known magnitude, and dividing the ice sheet into seven drainage basins. A summary of the inversion procedure is provided in the Technical Note of the GFZ RL06 Level 3 products ftp://isdcftp.gfz-potsdam.de/grace/GravIS/GFZ/ Level-3/ICE/GravIS_RL06_ICE_Technical_Note.pdf. Due to its proximity and possible signal overlaps, we additionally include Ellesmere Island in the estimation procedure. The gravity field signal arising from each basin and Ellesmere Island is calculated in the spectral domain, filtered identical to the GRACE/GRACE-FO data, and then adjusted in scale for each basin to least-squares minimize the difference between the modelled and observed spatial gravity field signal over the GrIS and Ellesmere Island. Using alternate GrIS mass change times series available at http://gravis.gfz-potsdam.de/home, which is based on the inversion schemes of ${ }^{59}$, as well as using AV RL06 with the inversion approach of ${ }^{28}$, we estimate that different assumptions underlying the gravimetric inversion introduce an uncertainty of \pm 25 Gt for the monthly estimate. These values are consistent with the \pm 26 Gt uncertainty presented in Table A.1 of $^{27}$ and included in our GrIS time series. More details on the inversion procedure is found in Sasgen et al. $2012^{27}$

Uncertainty of GrIS mass changes. To estimate the uncertainty of the GrIS monthly data arising from uncertainties in the GRACE/GRACE-FO coefficients, we first remove deterministic components from the time series of GrIS mass change, $M^{G}\left(t_{i}\right)$, consisting of bias, trend, annual, and semiannual and temporal variations longer than four months (using a moving average filter). The root-meansquared residual of the remaining mass variability $M_{\text {Res. }}^{G}\left(t_{i}\right)$ is considered noise. This estimate is conservative, as episodic mass changes and fluctuations below four months are included in the noise estimate. The same detrending procedure is applied to the GRACE/GRACE-FO coefficients' time series. Then, the noise level of each monthly solution is estimated by the cumulative degree-power of the residual GRACE/GRACE-FO coefficients $C_{j m}^{\text {Re }}\left(t_{i}\right)$ in the spectral range $j=40-60$,

$\sum_{j=40}^{60} \sum_{m=-j}^{j} C_{j m}^{R e s}\left(t_{i}\right)$, reflecting the noise level of the global gravity field solution. To get monthly uncertainties of mass change, we divide the global noise level of each monthly gravity field solution by the mean noise level for all gravity field months, and multiply this by the mean residual mass variability for the GrIS. Note that this noise level depends on latitude as the ground-track density of GRACE/ GRACE-FO measurements increases towards the poles (Supplementary Fig. 2). The uncertainty estimates for each SDS data set (GFZ RL06, CSR RL06 and JPL RL06) and the combination (AV RL06) are shown in Supplementary Fig. 5.

SMB-D. The SMB and its components over the GrIS are obtained from daily output of the Modèle Atmosphérique Régional (MAR) Version 3.10, run at $20 \mathrm{~km}$ resolution and 6-hourly forced by the NCEP-NCARv1 climate reanalyses ${ }^{29}$. The forcing with NCEP-NCARv1 enables near-real-time simulations of MARv3.10 used in this paper. Daily values are aggregated to monthly values by summation and integrated within the drainage basins of the contiguous ice sheet. The temporal coverage is January 1948 to December 2019. As an alternative SMB model, we employ RACMO2.3p2 at a resolution $1 \mathrm{~km}$ downscaled from $5.5 \mathrm{~km}^{30}$. The model is forced by ERA-40 (1958-1978) ${ }^{34}$ and ERA-Interim (1979-2019) ${ }^{60}$ and covers the time period January 1958 to August 2019.

The main SMB components shown are net accumulation (snowfall minus evaporation and sublimation) and meltwater runoff (meltwater production minus 
meltwater refreezing and deposition and retention). Uncertainties in the $\mathrm{SMB}^{36}$ are not presented in this paper, however, amount to roughly $\pm 22 \mathrm{Gt}$ for the total de-trended SMB (Supplementary Fig. 6). Note however, that uncertainties in the individual components may compensate each other and that both models may show biases with regard to the unknown true mean or long-term trend values of SMB. If possible, values for both MARv3.10 and RACMO2.3p2 are given in the text and figures, to provide an estimate of the effect of model setup, lateral forcing and grid resolution.

We use a temporally extended version of monthly-resolved ice discharge measurements from King et al. ${ }^{31}$, which includes glacier-scale discharge time series at all large (width $>1 \mathrm{~km}, N>200$ ) outlet glaciers. Changes in ice discharge are measured through flux gates drawn orthogonal to the mean direction of ice flow and are positioned within $5 \mathrm{~km}$ of the most retreated calving front positions, where valid data exist. Time-varying ice discharge records are derived by integrating changes in ice thickness, from differencing ASTER, SPOT-5 and ArcticDEM elevation data with BedMachine $\mathrm{v}^{61}$ bed topography, and velocity, from Landsat 7 and 8, RADARSAT 1 and 2, and TerraSAR/TanDEM-X. Velocity data gaps are filled at the individual glacier scale by applying a Kalman filter that uses the mean seasonal variability observed at each glacier. The 2-sigma uncertainty of $\mathrm{D}$ ranges between 10 and $20 \mathrm{Gt}_{\text {year }}{ }^{-1}$.

The estimated correction to reconcile GRACE/GRACE-FO and SMB-D trends for 2003-2019 amounts to $-7 \mathrm{Gt}_{\text {year }}{ }^{-1}$ (RACMO2.3p2 forced by ECMWF reanalysis) and $52 \mathrm{Gt}$ year $^{-1}$ (MARv3.10 forced by NCEP re-analysis). For completeness we state that the correction is $27 \mathrm{Gt} \mathrm{year}^{-1}$ and $26 \mathrm{Gt} \mathrm{year}^{-1}$ for MARv3.10 and MARv3.9 forced by ECMWF re-analysis, and $41 \mathrm{Gt}^{\text {year }}{ }^{-1}$ for MARv3.9 forced by NCEP re-analysis. Note that the correction for the previous version RACMO2.3p1 amounts to $59 \mathrm{Gt}$ year ${ }^{[-138}$.

Time series analysis. To enable a consistent comparison, we process the MARv3.10 output of mass changes similar to the GRACE/GRACE-FO time series. First, we calculate the cumulative sum of the MARv3.10 mass changes, representing storage variations of the ice sheet due to surface-mass balance and its components, $M^{M A R}(t)$, and subsample the time series by linear interpolation at the mid-point, $t_{i}$, of the GRACE measurement epochs (typically 30 days, but varying due to data quality), $M^{M A R}\left(t_{i}\right)$. To obtain mass fluxes, $\frac{d M\left(t_{i}\right)}{d t}$, presented in Fig. 3, we calculate the temporal derivative of the GRACE/GRACE-FO and interpolated MARv3.10 time series, using an unweighted central-difference scheme around $t_{i}$, involving the proceeding $\left(t_{i-1}\right)$ and succeeding $\left(t_{i+1}\right)$ time step. Note that this procedure acts as a moderate smoothing filter, reducing the peak values compared to the initial monthly mass fluxes from MARv3.10. Biennial mass balances are determined by unweighted fitting of piecewise linear functions to the mass time series with breakpoints in January 1st of every second year, without prior removal of annualor semi-annual components. Time intervals are centred on summer peak losses to encompass the complete melt seasons, and to allow us to bridge the gap between GRACE and GRACE-FO in 2017-2018. The climatological mean of the seasonal mass fluxes from GRACE (Fig. 3) is obtained by linearly interpolating the GRACE time series $\frac{d M\left(t_{i}\right)}{d t}$ to regular monthly time intervals, excluding data gaps, followed by unweighted averaging.

\section{Data availability}

All GRACE/GRACE-FO data used in this paper are freely available from the websites of the SDS centres; Level-2 data as well as supporting documentation may be accessed at http://podaac.jpl.nasa.gov and http://isdc.gfz-potsdam.de for GFZ RL06: https://doi.org/ 10.5880/GFZ.GRACE_06_GSM, https://doi.org/10.5880/GFZ.GRACEFO_06_GSM; JPL RL06: https://doi.org/10.5067/GRGSM-20J06, https://doi.org/10.5067/GFL20-MJ060 CSR RL06: https://doi.org/10.5067/GRGSM-20C06, https://doi.org/10.5067/GFL20MC060 (GRACE, GRACE-FO, respectively). User-friendly, gridded maps of mass change (Level-3 data) are available from https://grace.jpl.nasa.gov/ (JPL), http://www2.csr.utexas. edu (CSR) and http://gravis.gfz-potsdam.de/home (GFZ).

Output of the Modèle Atmosphérique Régional (MAR) Version 3.9 representing the surface-mass balance of Greenland are available from ftp://ftp.climato.be/fettweis/. NCEP Reanalysis data is provided by the NOAA/OAR/ESRL PSD, Boulder, Colorado, USA, from their Web site at https://www.esrl.noaa.gov/psd/. Analysis contributing to this paper contain modified Copernicus Climate Change Service Information 201962; https:// doi.org/10.24381/cds.6860a573.

RACMO2.3p2 output of the surface-mass balance and its components are freely available from the authors upon request and without conditions. To submit a request, please contact Brice Noël: b.p.y.noel@uu.nl.

Dynamic ice discharge data are available upon request from Michalea D. King: michaleaking@gmail.com.

The NAO and GBI indices are obtained from the National Oceanic and Atmospheric Administration (NOAA), Climate Prediction Center, https://www.cpc.ncep.noaa.gov/ products/precip/CWlink/pna/nao.shtml (last accessed, 30 December 2019) and the Earth System Research Laboratory, https://www.esrl.noaa.gov/psd/gcos_wgsp/Timeseries/ GBI_UL/ (last accessed, 30 December 2019), respectively.

Data underlying Figs. 1, 2, 3 and 5 are accessible at https://doi.org/10.1594/ PANGAEA.919670. The visualization of the atmospheric fields (Fig. 4) from NCEP reanalysis and other datasets can done at https://psl.noaa.gov/cgi-bin/data/composites/.

\section{Code availability}

Spherical harmonic functions were handled using the software package of Frederik J. Simons, kindly provided at http://geoweb.princeton.edu/people/simons/software.html (last accessed, 26 June 2020).

Received: 19 June 2020; Accepted: 1 July 2020; Published online: 20 August 2020

\section{References}

1. Kjeldsen, K. K. et al. Spatial and temporal distribution of mass loss from the Greenland Ice Sheet since AD 1900. Nature 528, 396-400 (2015).

2. Cazenave, A., Meyssignac, B. \& Merchant, C. Global sea level budget 1993present. Earth Syst. Sci. Data 10, 1551-1590 (2018).

3. Mouginot, J. et al. Forty-six years of Greenland Ice Sheet mass balance from 1972 to 2018. Proc. Natl. Acad. Sci. 116, 9239-9244 (2019).

4. van den Broeke, M. et al. Partitioning recent Greenland mass loss. Science 326, 984-986 (2009)

5. Box, J. E., Yang, L., Bromwich, D. H. \& Bai, L.-S. Greenland Ice Sheet surface air temperature variability: 1840-2007*. J. Clim. 22, 4029-4049 (2009).

6. McGrath, D., Colgan, W., Bayou, N., Muto, A. \& Steffen, K. Recent warming at Summit, Greenland: Global context and implications. Geophys. Res. Lett. 40, 2091-2096 (2013)

7. Riihelä, A., King, M. D. \& Anttila, K. The surface albedo of the Greenland Ice Sheet between 1982 and 2015 from the CLARA-A2 dataset and its relationship to the ice sheet's surface mass balance. The Cryosphere, 13, 2597-2614 (2019).

8. Ryan, J. C. et al. Greenland Ice Sheet surface melt amplified by snowline migration and bare ice exposure. Sci. Adv. 5, eaav3738 (2019).

9. Hall, D. et al. A multilayer surface temperature, surface albedo, and water vapor product of Greenland from MODIS. Remote Sens 10, 555 (2018).

10. Niwano, M., Hashimoto, A. \& Aoki, T. Cloud-driven modulations of Greenland ice sheet surface melt. Sci. Rep. 9, 10380 (2019).

11. Pithan, F. \& Mauritsen, T. Arctic amplification dominated by temperature feedbacks in contemporary climate models. Nat. Geosci. 7, 181-184 (2014).

12. Mottram, R. et al. An integrated view of Greenland Ice Sheet mass changes based on models and satellite observations. Remote Sens. 11, 1407 (2019).

13. The IMBIE Team. Mass balance of the Greenland Ice Sheet from 1992 to 2018. Nature 579, 233-239 (2020)

14. Velicogna, I. et al. Continuity of ice sheet mass loss in Greenland and Antarctica from the GRACE and GRACE follow-onmissions. Geophys. Res. Lett. e2020GL087291, 1-8 (2020).

15. Enderlin, E. M. et al. An improved mass budget for the Greenland Ice Sheet. Geophys. Res. Lett. 41, 866-872 (2014).

16. Hanna, E., Cropper, T. E., Hall, R. J. \& Cappelen, J. Greenland Blocking Index 1851-2015: a regional climate change signal. Int. J. Climatol. 36, 4847-4861 (2016).

17. Hanna, E., Fettweis, X. \& Hall, R. J. Brief communication: recent changes in summer Greenland blocking captured by none of the CMIP5 models. Cryosphere 12, 3287-3292 (2018)

18. Hanna, E. et al. Atmospheric and oceanic climate forcing of the exceptional Greenland ice sheet surface melt in summer 2012. Int. J. Climatol. 34, 1022-1037 (2014).

19. Hofer, S., Tedstone, A. J., Fettweis, X. \& Bamber, J. L. Decreasing cloud cover drives the recent mass loss on the Greenland Ice Sheet. Sci. Adv. 3, e1700584 (2017).

20. Bennartz, R. et al. July 2012 Greenland melt extent enhanced by low-level liquid clouds. Nature 496, 83-86 (2013).

21. Tedesco, M. et al. Evidence and analysis of 2012 Greenland records from spaceborne observations, a regional climate model and reanalysis data. Cryosphere 7, 615-630 (2013).

22. Tedesco, M. et al. The role of albedo and accumulation in the 2010 melting record in Greenland. Environ. Res. Lett. 6, 014005 (2011).

23. Tapley, B. D. et al. Contributions of GRACE to understanding climate change. Nat. Clim. Change 9, 358-369 (2019).

24. Tapley, B. D., Bettadpur, S., Watkins, M. \& Reigber, C. The gravity recovery and climate experiment: mission overview and early results. Geophys. Res. Lett. 31, L09607 (2004).

25. Flechtner, F. et al. What can be expected from the GRACE-FO laser ranging interferometer for Earth science applications? In Remote Sensing and Water Resources 263-280 (Springer, 2016).

26. Vishwakarma, B., Devaraju, B. \& Sneeuw, N. What is the spatial resolution of GRACE products for hydrology? Remote Sens 10, 852 (2018).

27. Sasgen, I. et al. Timing and origin of recent regional ice-mass loss in Greenland. Earth Planet. Sci. Lett. 333, 293-303 (2012).

28. Wouters, B., Chambers, D. \& Schrama, E. J. O. GRACE observes small-scale mass loss in Greenland. Geophys. Res. Lett. 35, L20501 (2008). 
29. Fettweis, X. et al. Reconstructions of the 1900-2015 Greenland ice sheet surface mass balance using the regional climate MAR model. Cryosphere 11, 1015-1033 (2017).

30. Noël, B., van de Berg, W. J., Lhermitte, S. \& van den Broeke, M. R. Rapid ablation zone expansion amplifies north Greenland mass loss. Sci. Adv. 5, eaaw0123 (2019)

31. King, M. D. et al. Seasonal to decadal variability in ice discharge from the Greenland Ice Sheet. The Cryosphere 12, 3813-3825 (2018).

32. Delhasse, A. et al. Brief communication: evaluation of the near-surface climate in ERA5 over the Greenland Ice Sheet. Cryosphere 14, 957-965 (2020).

33. Kalnay, E. et al. The NCEP/NCAR 40-year reanalysis project. Bull. Am. Meteorol. Soc 77, 437-472 (1996).

34. Uppala, S. M. et al. The ERA-40 re-analysis. Q. J. R. Meteorol. Soc 131, 2961-3012 (2005).

35. Mankoff, K. D. et al. Greenland Ice Sheet solid ice discharge from 1986 through 2017. Earth Syst. Sci. Data 11, 769-786 (2019).

36. Vernon, C. L. et al. Surface mass balance model intercomparison for the Greenland Ice Sheet. Cryosphere 7, 599-614 (2013).

37. Noël, B. et al. Modelling the climate and surface mass balance of polar ice sheets using RACMO2 - Part 1: Greenland (1958-2016). Cryosphere 12, 811-831 (2018).

38. Khazendar, A. et al. Interruption of two decades of Jakobshavn Isbrae acceleration and thinning as regional ocean cools. Nat. Geosci. 12, 277-283 (2019).

39. Francis, J. A. \& Vavrus, S. J. Evidence for a wavier jet stream in response to rapid Arctic warming. Environ. Res. Lett. 10, 014005 (2015).

40. Serreze, M. C. \& Barry, R. G. Processes and impacts of Arctic amplification: a research synthesis. Glob. Planet. Change 77, 85-96 (2011).

41. Beer, E., Eisenman, I. \& Wagner, T. J. W. Polar amplification due to enhanced heat flux across the halocline. Geophys. Res. Lett. 47, e2019GL086706 (2020).

42. Pachauri, R.K. et al. Climate change 2014: synthesis report. Contribution of Working Groups I, II and III to the fifth assessment report of the Intergovernmental Panel on Climate Change. (IPCC, 2014).

43. Rajewicz, J. \& Marshall, S. J. Variability and trends in anticyclonic circulation over the Greenland ice sheet, 1948-2013. Geophys. Res. Lett. 41, 2842-2850 (2014).

44. Bevis, M. et al. Accelerating changes in ice mass within Greenland, and the ice sheet's sensitivity to atmospheric forcing. Proc. Natl. Acad. Sci. 116, 1934-1939 (2019).

45. Pattyn, F. et al. The Greenland and Antarctic ice sheets under $1.5^{\circ} \mathrm{C}$ global warming. Nat. Clim. Change 8, 1053-1061 (2018).

46. Moon, T., Joughin, I. \& Smith, B. Seasonal to multiyear variability of glacier surface velocity, terminus position, and sea ice/ice mélange in northwest Greenland. J. Geophys. Res. Earth Surf 120, 818-833 (2015).

47. Slater, D. A. et al. Estimating Greenland tidewater glacier retreat driven by submarine melting. Cryosphere 13, 2489-2509 (2019).

48. Dahle, C. et al. The GFZ GRACE RL06 monthly gravity field time series: processing details and quality assessment. Remote Sens. 11, 2116 (2019).

49. Bettadpur, S. GRACE UTCSR Level-2 Processing Standards Document For Level-2 Product Release 0006. http://isdcftp.gfz-potsdam.de/grace/DOCUMENTS/Level-2/ GRACE_CSR_L2_Processing_Standards_Document_for_RL06.pdf (2018).

50. Save, H. GRACE Follow-On CSR Level-2 Processing Standards Document http://isdcftp.gfz-potsdam.de/grace-fo/DOCUMENTS/Level-2/GRACEFO_CSR_L2_Processing_Standards_Document_for_RL06.pdf (2019).

51. Yuan, D.-N. GRACE Follow-On JPL Level-2 Processing Standards Document For Level-2 Product Release 06. http://icgem.gfz-potsdam.de/GRACEFO_JPL_L2 Processing_Standards_Document_for_RL06.pdf (2019).

52. Sun, Y., Riva, R. \& Ditmar, P. Optimizing estimates of annual variations and trends in geocenter motion and $J_{2}$ from a combination of GRACE data and geophysical models. J. Geophys. Res. Solid Earth 121, 8352-8370 (2016).

53. Swenson, S., Chambers, D. \& Wahr, J. Estimating geocenter variations from a combination of GRACE and ocean model output. J. Geophys. Res. 113, B08410 (2008).

54. Cheng, M., Tapley, B. D. \& Ries, J. C. Estimating geocenter variations from a combination of GRACE and ocean model output. J. Geophys. Res. 113, B08410 (2008).

55. Loomis, B. D., Rachlin, K. E., Wiese, D. N., Landerer, F. W. \& Luthcke, S. B. Replacing GRACE/GRACE-FO C_\{30\} with satellite laser ranging: Impacts on Antarctic Ice Sheet mass change. Geophys. Res. Lett. 47, e2019GL085488 (2020).

56. Bandikova, T., McCullough, C., Kruizinga, G. L., Save, H. \& Christophe, B. GRACE accelerometer data transplant. Adv. Space Res. 64, 623-644 (2019).
57. Khan, S. A. et al. Geodetic measurements reveal similarities between post-Last Glacial Maximum and present-day mass loss from the Greenland Ice Sheet. Sci. Adv 2, e1600931 (2016)

58. Jean, Y., Meyer, U. \& Jäggi, A. Combination of GRACE monthly gravity field solutions from different processing strategies. J. Geod 92, 1313-1328 (2018).

59. Groh, A. et al. Evaluating GRACE mass change time series for the Antarctic and Greenland Ice Sheet-Methods and results. Geosciences 9, 415 (2019).

60. Dee, D. P. et al. The ERA-Interim reanalysis: configuration and performance of the data assimilation system. Q. J. R. Meteorol. Soc. 137, 553-597 (2011).

61. Morlighem, M. et al. BedMachine v3: Complete bed topography and ocean bathymetry mapping of Greenland from multibeam echo sounding combined with mass conservation. Geophys. Res. Lett. 44, 11,051-11,061 (2017).

62. Copernicus Climate Change Service. ERA5: Fifth generation of ECMWF atmospheric reanalyses of the global climate. https://cds.climate.copernicus.eu/ cdsapp\#!/home (2017)

\section{Acknowledgements}

I.S. acknowledges funding by the Helmholtz Climate Initiative REKLIM (Regional Climate Change), a joint research project of the Helmholtz Association of German Research Centres (HGF). I.S. acknowledges support by the Open Access Publication Funds of Alfred-Wegener-Institut Helmholtz-Zentrum für Polar- und Meeresforschung. B.W. was funded by NWO VIDI grant 016.Vidi.171.063. A.G. received funding from the NASA Cryosphere Science program. C.D. acknowledges funding of the development of the GRACE-Follow On Science Data System by the German Federal Ministry of Education and Research (BMBF) under grant 03F0654A. A.G.'s and F.L.'s research was carried out at the Jet Propulsion Laboratory/California Institute of Technology, under a contract with the National Aeronautics and Space Administration. M.T. would like to acknowledge financial support by the National Science Foundation (PLR- 1603331, PLR1713072, OPP 19-01603), NASA (NNX17AH04G, 80NSSC17K0351), and the HeisingSimons Foundation. Open access funding provided by Projekt DEAL.

\section{Author contributions}

I.S., B.W. and A.G. developed the study and carried out the majority of the data analysis, with contributions from M.K., X.F., C.D., F.L., M.T. and H.S. X.F. provided MAR model output and the analysis of the GBI and NAO indices. An updated data set of temporal variations in ice-dynamic discharge of the Greenland Ice Sheet was contributed by M.K. All authors contributed to the writing and editing of the paper.

\section{Competing interests}

The authors declare no competing interests.

\section{Additional information}

Supplementary information is available for this paper at https://doi.org/10.1038/s43247 020-0010-1.

Correspondence and requests for materials should be addressed to I.S.

Peer review information Primary handling editor: Heike Langenberg.

Reprints and permission information is available at http://www.nature.com/reprints

Publisher's note Springer Nature remains neutral with regard to jurisdictional claims in published maps and institutional affiliations.

Open Access This article is licensed under a Creative Commons Attribution 4.0 International License, which permits use, sharing, adaptation, distribution and reproduction in any medium or format, as long as you give appropriate credit to the original author(s) and the source, provide a link to the Creative Commons license, and indicate if changes were made. The images or other third party material in this article are included in the article's Creative Commons license, unless indicated otherwise in a credit line to the material. If material is not included in the article's Creative Commons license and your intended use is not permitted by statutory regulation or exceeds the permitted use, you will need to obtain permission directly from the copyright holder. To view a copy of this license, visit http://creativecommons.org/ licenses/by/4.0/.

(c) The Author(s) 2020 